\title{
Profiles of Soluble Protein During Sporulation of Bacillus subtilis
}

\author{
By W. M. WAITES* AND D. G. WILD \\ Microbiology Unit, Department of Biochemistry, University of Oxford, \\ South Parks Road, Oxford, OXI $3 Q U$
}

(Accepted for publication 4 February 1970)

SUMMARY

Electrophoresis in polyacrylamide gels of soluble proteins from Bacillus subtilis showed changing patterns of bands during sporulation. Somewhat different patterns were obtained from extracts of three asporogenous mutants exposed to a sporulation medium but the differences did not correlate well with the stages in sporulation at which the mutants were believed to be blocked.

\section{INTRODUCTION}

Spore formation in bacilli is accompanied by complex metabolic changes (reviewed by Murrell (1967) and Mandelstam (1969)). These include synthesis of enzymes directly involved in formation of spore-specific components and of others whose appearance is correlated with the seven morphologically distinct stages(Ryter, Schaeffer \& Ionesco, 1966) of sporulation. More indirect alterations in enzymic machinery may result from experimental procedures used to induce commitment to spore formation; for example, derepression of synthesis of certain enzymes may occur if a nutritionally defective medium is used. Moreover, sporulating bacteria contain one or more proteases responsible for a high rate of turnover of protein; a consequence is that, in Bacillus subtilis, nearly all the protein in the spore is newly made during sporulation (Mandelstam \& Waites, I968).

Electrophoresis in polyacrylamide gels provides a sensitive indication of differences in the composition of the soluble protein fraction of bacteria at different stages in the growth cycle and in exponential growth in different media (Raunio \& Sarimo, I965; Moses \& Wild, 1969). We have used this technique to monitor changes that occur after suspension in sporulation medium of a sporogenic organism and of asporogenous mutants derived from it. Such an electrophoretic technique might supplement biochemical and morphological criteria to determine the point in spore formation at which a particular mutation leading to asporogeny is expressed. In particular, a mutant blocked at a very early stage of spore formation has been compared with the corresponding wild-type organism in an attempt to distinguish changes in the soluble protein fraction due to sporulation itself from changes less directly associated with the process.

* Present address: Agricultural Research Council Food Research Institute, Colney Lane, Norwich, Norfolk, NOR 7oF. 


\section{METHODS}

Organisms. Bacillus subtilis (Marburg strain 168) requires indole or tryptophan for growth but is sporogenic and is called the 'wild-type'. Three asporogenous mutants from this parent were: E22, which forms neither the protease nor antibiotic characteristic of Stage I of sporulation. An unpublished morphological examination by D. Kay shows that mutant E22 retains the characteristic appearance of vegetative organisms under conditions in which the wild-type sporulates. Mutants E3I and A 23 synthesize protease, antibiotic, alkaline phosphatase and glucose dehydrogenase in a sporulation medium but form only 'phase-grey' refractile bodies and do not make dipicolinic acid. On biochemical grounds (Warren, 1968) they therefore probably complete only Stages I to III of sporulation. This view is supported by unpublished electron microscopy by D. Kay.

Growth and preparation of extracts. Organisms were shaken overnight at $37^{\circ}$ in the hydrolysed casein medium of Donnellan, Nags \& Levinson (1964) with glucose omitted. A culture (containing about $0.25 \mathrm{mg}$. dry wt organisms $/ \mathrm{ml}$.) was centrifuged and the organisms resuspended in the same volume of the defined sporulation medium of Donnellan et al. (1964) except that glucose was omitted and $\mathrm{MgSO}_{4}$ was $40 \mathrm{~mm}$. This latter medium normally causes a high incidence of spores in about $8 \mathrm{hr}$. At intervals, $200 \mathrm{ml}$. samples were harvested and the organisms resuspended in 0.5 or $\mathrm{I} \cdot 0 \mathrm{ml}$. ice-cold buffer containing $10 \mathrm{~mm}$-tris- $\mathrm{HCl}$, $100 \mathrm{~mm}-\mathrm{KCl}$, $10 \mathrm{~mm}$-magnesium acetate, $\mathrm{pH} 7.4$. Samples were maintained at $0^{\circ}$ and the organisms broken with an ultrasonic disintegrator (M.S.E. Ltd.) used intermittently for a total of $5 \mathrm{~min}$. The suspension was then centrifuged at $40,000 \mathrm{rev} . / \mathrm{min}$. for $\mathrm{I}^{\circ} 5 \mathrm{hr}$ at $4^{\circ}$ in a M.S.E. 'Superspeed $50^{\prime}$ ' centrifuge to remove cell debris and ribosomes. Protein in the supernatants was estimated by the method of Lowry, Rosebrough, Farr \& Randall (I95I). In a control experiment, portions of bacterial suspension were taken after o and $6 \mathrm{hr}$, centrifuged, and the organisms resuspended in Io ml. buffer and broken with a Braun MSK cell homogenizer (Shandon Scientific Co.). After removal of debris and ribosomes, extracts prepared by this latter method were concentrated by pressure dialysis. Profiles of soluble protein were not significantly different from those obtained by sonication.

Polyacrylamide gel electrophoresis. An apparatus was used in which flat slabs of gel (about $16 \times 18 \mathrm{~cm}$.) were cast between plates cooled with tap water during electrophoresis. Up to ro samples could be examined in the same gel from parallel slots. The gels were made from $7.5 \%$ 'cyanogum $4 \mathrm{I}$ ' and $0 . \mathrm{I} \%(\mathrm{v} / \mathrm{v}) \mathrm{N}, \mathrm{N}, \mathrm{N}^{\prime}, \mathrm{N}^{\prime}$-tetramethyl-

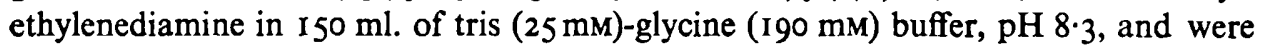
polymerized by adding ammonium persulphate $(0.12 \%$, w/v). The same buffer was used in the electrode vessels. Electrophoresis was carried out for about $2 \mathrm{hr}$, at first with a current of $90 \mathrm{~mA}(200 \mathrm{~V})$. During a run, the voltage rose to $400 \mathrm{~V}$ and was then kept constant; as a consequence, the current had decreased to about $60 \mathrm{~mA}$ by the end.

Extracts for electrophoresis were diluted when necessary with the tris-KCl-magnesium acetate buffer to $3 \mathrm{mg}$. protein $/ \mathrm{ml}$. To $0.1 \mathrm{ml}$. portions were added Io $\mathrm{mg}$. sucrose and Io $\mu \mathrm{l}$. $0.1 \%$ (w/v) bromophenol blue. A sample (30 $\mu \mathrm{l}$.) was loaded for electrophoresis. At the end of a run protein bands were stained by immersing the slab of gel for $\mathrm{I}$ hr in a solution of naphthalene black $\mathrm{I} 2 \mathrm{~B}(0 . \mathrm{I} \% \mathrm{w} / \mathrm{v})$ in acetic acidmethanol-water $(2: 5: 13, v / v / v)$; excess stain was removed by washing with frequent 
changes of $7.5 \%(\mathrm{v} / \mathrm{v})$ acetic acid. The gels were subsequently sliced and the protein patterns of the individual samples scanned by reflectance in a Joyce-Loebl 'Chromoscan' using the 5-042 filter.

\section{RESULTS}

\section{Profiles from wild-type}

Extract of the wild-type gave a pattern in which discrete protein bands were superposed on background stain. This background was minimized by a visual inspection but was much more apparent when gels were scanned photoelectrically in a semiquantitative manner. More bands could usually be seen by eye than were clearly resolved by the densitometer. Figure I contains a visual representation of protein distribution for comparison with that given by a densitometer tracing of the same gel: some fine detail was lost in redrawing the densitometer curves.

Traces for samples derived from the wild-type organism after, $0,1,2,4$ and $6 \mathrm{hr}$ incubation in the sporulation medium are shown in Fig. I. The major peaks are numbered and components of the same mobility (confirmed by visual inspection of the gels) are given the same number in the sequential samples. There was a constant change of protein profile during incubation although some peaks (for example, 6, 9, Io) varied little in relative prominence. Some components (II, I2, I3) declined markedly in the samples taken at early times, and peaks I 2 and 13 decreased throughout the experimental period. Peak 3 was most prominent in the sample taken at $2 \mathrm{hr}$; peak 8 also reached a maximum after $\mathrm{I}$ to $2 \mathrm{hr}$. Peak $\mathrm{I} 8$ was particularly noticeable in the $6 \mathrm{hr}$ sample. New protein bands (e.g. peaks 16 and 17 ) appeared at different times and thereafter increased in prominence. The major protein band in all samples except the last was peak 7. At $6 \mathrm{hr}$ this region of the profile was much less prominent and the major peak (19) had a mobility slightly greater than peak 7 . This change was observed in a number of different experiments. The most striking change in these profiles was, however, in peak I. At first this was minor, but it increased steadily in prominence until in the $6 \mathrm{hr}$ sample it was the major component of the profile. Similar changes in peak I were found consistently in different experiments, as were many of the other alterations referred to above. However, the degree of resolution of these complex patterns varied from one electrophoresis run to another. It was therefore desirable to compare samples in the same gel slab. Extracts prepared from organisms grown for separate experiments also differed somewhat in their profiles because slight alterations in cultural conditions may have affected the proportions of the different proteins in the cytoplasm.

\section{Profiles from mutant organisms}

Figure 2 shows the densitometer traces of samples taken following incubation in the resuspension medium of the asporogenous mutant E22. Samples were examined in the same gel slab as those of Fig. I. Where possible, peaks have been numbered to correspond with those of the same mobility in the wild-type strain (this equivalence was confirmed by visual comparison of the gels) but are distinguished by a superscript ('). The protein profile at zero time was very similar to that of the wild-type organism. Mutant E22 grew rather less well in the casein hydrolysate medium than the wild-type, so that some differences were to be expected. The samples taken after resuspension in sporulation medium showed marked changes, several of which were similar to those in the wild-type. For example, peaks $1 \mathrm{I}^{\prime}, \mathrm{I}^{\prime}{ }^{\prime}$ and $13^{\prime}$ decreased in 
later samples; peak $16^{\prime}$ was not visible at zero time but appeared subsequently; peak $3^{\prime}$ at first increased in relative intensity but then almost disappeared. However, the profiles of mutant E 22 differed from those of the wild-type in several respects. For example,

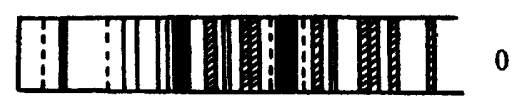

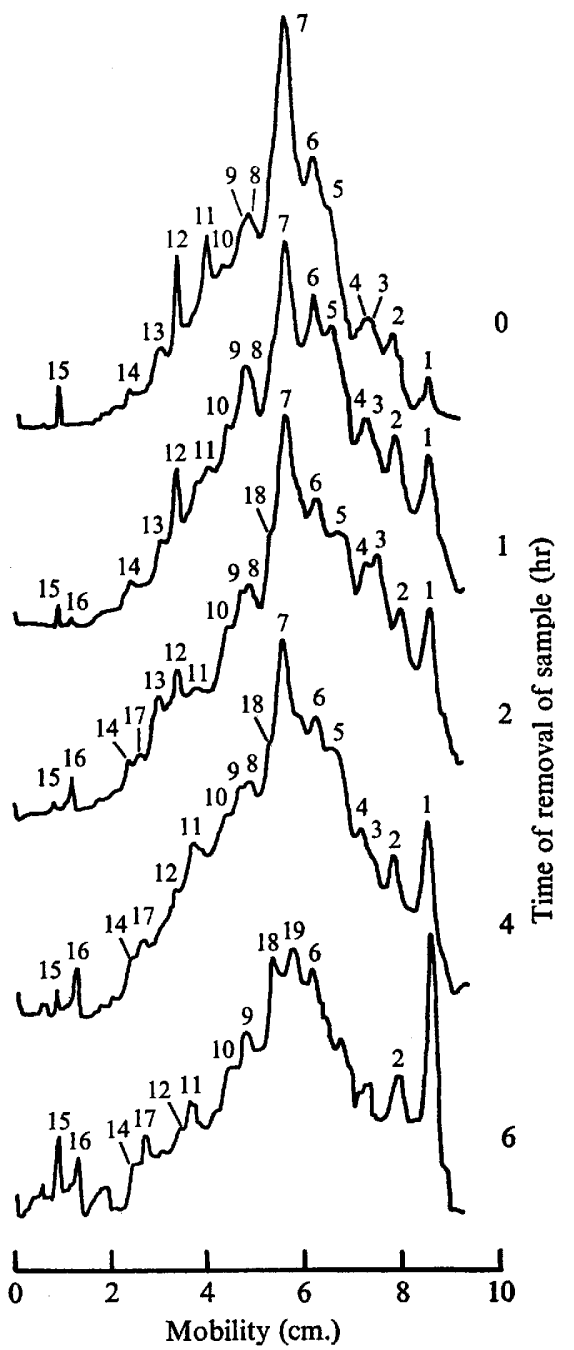

Fig. I

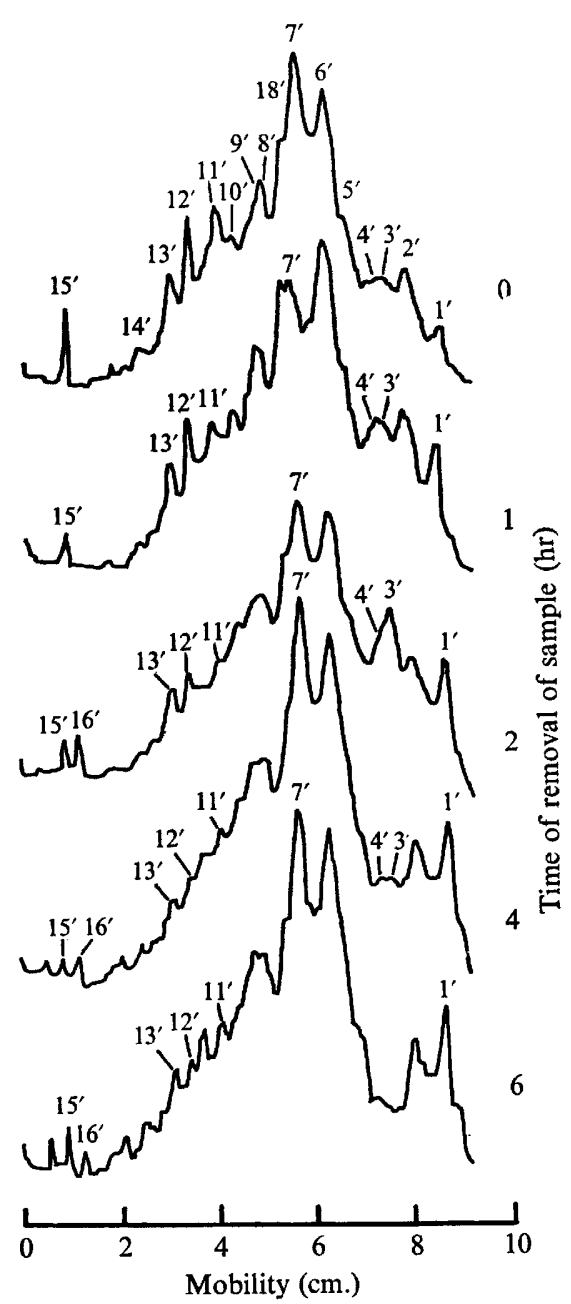

Fig. 2

Fig. I. Profiles of soluble proteins from Bacillus subtilis Marburg strain I 68 taken at different times after resuspension in sporulation medium. Preparation of samples and electrophoretic separation of proteins are described in the text. After electrophoresis, the bromophenol blue marker dye had migrated about $14 \mathrm{~cm}$. Some very minor diffuse components of mobility greater than that of peak I are not shown. For the sample taken at zero time the densitometer trace is compared with a visual representation of the gel.

Fig. 2. Profiles of soluble proteins from mutant E 22 taken at different times after resuspension in sporulation medium. Electrophoresis was in the same gel as that used in Fig. I. Experimental procedures are given in the text. 
peak $13^{\prime}$ was present in all samples of mutant E 22 whereas in the wild-type the corresponding component was not resolved after $4 \mathrm{hr}$. The considerable changes in peak 7 of the wild-type that occurred between 4 and $6 \mathrm{hr}$ did not take place in mutant $\mathrm{E} 22$; in general, the profile of this mutant after $6 \mathrm{hr}$ differed much less from the previous $(4 \mathrm{hr})$ sample than for the wild-type. This was evident when the overall distribution of proteins in the samples were compared but applied particularly to peak I'. At $6 \mathrm{hr}$ peak I was the major component in the wild-type and increased very considerably in prominence from $4 \mathrm{hr}$; in contrast, although peak $\mathrm{I}^{\prime}$ at first increased, there was little difference between the 4 and $6 \mathrm{hr}$ samples.

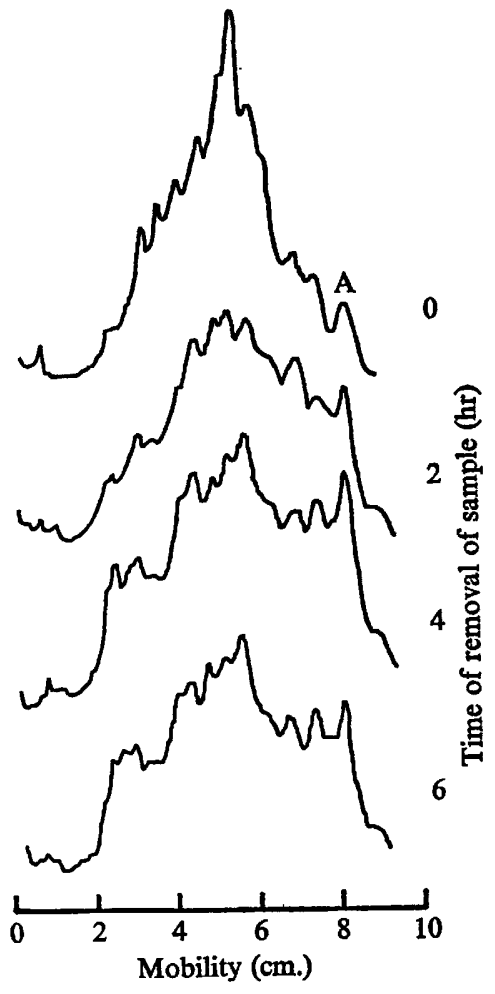

Fig. 3

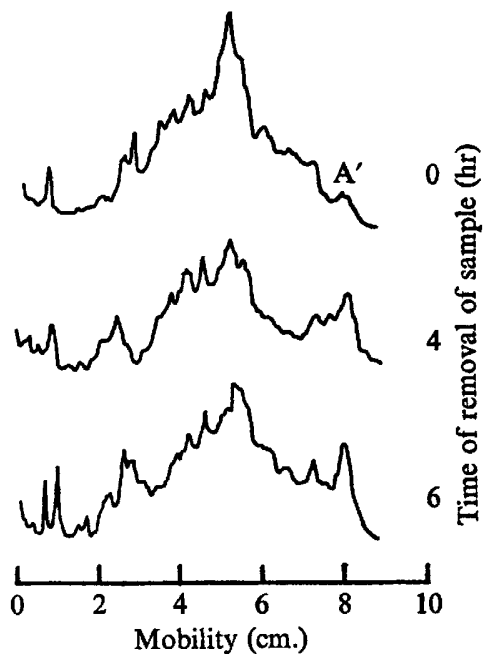

Fig. 4

Fig. 3. Profiles of soluble proteins from mutant E3I taken at different times after resuspension in sporulation medium. Experimental procedures were as for Fig. I and as described in the text.

Fig. 4. Profiles of soluble proteins from mutant A 23 taken at different times after resuspension in sporulation medium. Experimental procedures were as for Fig. I and as described in the text, except that the cell-free extracts used for electrophoresis contained $1 \cdot 5 \mathrm{mg}$. protein $/ \mathrm{ml}$.

Two other asporogenous mutants were examined in less detail. Results with E3I are in Fig. 3. This mutant is able to proceed as far as Stage IV of spore formation; sporulation processes should thus be almost normal for about $4 \mathrm{hr}$. The protein profile at zero time was similar to those of mutant E22 and the wild-type and changed considerably in the sample taken after $4 \mathrm{hr}$. This redistribution of proteins again involved an increase in the prominence of peak $A$ which corresponds to peaks $I$ and $I^{\prime}$ 
of Fig. I and 2. The 4 and $6 \mathrm{hr}$ samples were extremely similar so that, as with mutant E22, the late changes apparently characteristic of the wild-type were not observed. Results with mutant A23 (Fig. 4) were rather similar in that the protein profile altered greatly during the first $4 \mathrm{hr}$. However, there were rather more changes in the following $\mathbf{2} \mathbf{~ h r}$ than with the other two mutants. Peak $\mathrm{A}^{\prime}$ was minor at zero time and at first increased considerably. Although this component was rather more prominent in the $6 \mathrm{hr}$ sample, the increase was much less than in the wild-type organism.

\section{DISCUSSION}

Electrophoresis of soluble proteins prepared at intervals from a sporogenic organism reveals a pattern of complex changes. These experiments show that electrophoresis in polyacrylamide gels provides a sensitive indication of changing cytoplasmic conditions during spore formation. Interpretation of the changes observed is rendered difficult by several factors. Although many components are satisfactorily resolved in the gels, each of these is likely to be a mixture of otherwise dissimilar proteins. Moreover, like many other analyses of events during spore formation, the relevance of the observed changes to sporulation per se is unknown; for example, some of the alterations in the profiles could be a consequence of the growth conditions necessary to induce commitment. An unexpected finding is that, during incubation of mutant $\mathrm{E} 22$ in sporulation medium, considerable changes occurred in the profiles during the first $4 \mathrm{hr}$, some of which closely parallelled those observed in the wild-type strain. Mutant E22 is, as stated in Methods, thought to be unable to participate in the first stages of spore formation and to synthesize none of the proteins associated specifically with the various morphological events (Warren, 1968). In particular, this mutant lacks the protease normally responsible for a high rate of protein turnover in organisms in sporulation medium (Mandelstam \& Waites, 1968). The considerable redistribution of proteins in the absence of turnover is presumably made possible by a slow increase in net protein content under the conditions of our experiments. The close association of the protease with the ability to sporulate is puzzling and factors that may be involved have been discussed by Mandelstam (1969). That there are considerable changes in the profiles of mutant E22 similar to some of those found in the wild-type suggests that many of the alterations observed in all the organisms tested may be more a consequence of altered nutritional conditions consequent upon resuspension of organisms in sporulation medium than a result of changes directly concerned with sporulation itself.

The major difference noted between the mutants and the wild-type was that profiles from the former after 4 and $6 \mathrm{hr}$ differed little; in particular, the large increase in peak I characteristic of the wild-type did not occur. The increase in prominence of this electrophoretic component may therefore be more directly related to events in sporulation than some of the changes observed. But because the mutants can effect some increase in the proportion of material of this mobility during the early stages of incubation, the relevance of this observation to spore formation requires further clarification. Moreover, the time during incubation at which the 'freezing' of profiles of soluble protein takes place is not directly related to the point in spore formation at which, on biochemical and morphological grounds, the mutants are thought to be blocked. Thus, although asporogenous mutants differ from the wild-type in their behaviour, these 
differences are not yet sufficiently well defined to enable mutants to be ordered by an examination of their profiles of soluble protein.

This work was supported by the Science Research Council. We are grateful to Mrs D. Torgerson for technical help and to Dr R. E. MacDonald for loaning the electrophoresis cell.

\section{REFERENCES}

Donnellan, J. E., NaGs, E. H. \& Levinson, H. S. (1964). Chemically defined, synthetic media for sporulation and for germination and growth of Bacillus subtilis. Journal of Bacteriology 87, 332.

Lowry, O. H., Rosebrough, N. J., Farr, A. L. \& Randall, R. J. (195I). Protein measurement with the Folin phenol reagent. Journal of Biological Chemistry 193, 265.

Mandelstam, J. (1969). Regulation of bacterial spore formation. In Microbial Growth. Symposia of the Society for General Microbiology 19, 377.

MANDELSTAM, J. \& WAITES, W. M. (I968). Sporulation in Bacillus subtilis. The role of exoprotease. Biochemical Journal ro9, 793.

MurRell, W. G. (1967). The biochemistry of the bacterial endospore. In Advances in Microbial Physiology, vol. 1, p. I33. Edited by A. H. Rose \& J. F. Wilkinson. London and New York: Academic Press.

Moses, V. \& WIID, D. G. (1969). Soluble protein profiles in Escherichia coli. Folia Microbiologica, Praha 14, 305.

RaUnio, R. \& Sarimo, S. (1965). Changes in protein composition of Escherichia coli during the active growth phase. Acta Chemica Scandinavica 19, 2428.

RYTER, A., SCHAefFer, P. \& IonesCo, H. (1966). Classification cytologique, par leur stade de blocage, des mutants de sporulation de Bacillus subtilis Marburg. Annales de l'Institut Pasteur, Paris Iro, 305.

WARREN, S. C. (1968). Sporulation in Bacillus subtilis: Biochemical changes. Biochemical Journal I09, 81 I. 